\title{
Efficacy of standardized novel Boswellia serrata extract in the dextran sodium sulfate-induced colitis model - potential use in gut health management
}

\author{
Shefali Thanawala ${ }^{1 *}$, Rajat Shah ${ }^{1}$, Prasanna Katnapally ${ }^{2}$, Upendra Bhatnagar ${ }^{2}$
}

\author{
${ }^{1}$ Medical Affairs, Inventia Healthcare Limited, Mumbai, Maharashtra, India \\ ${ }^{2}$ Preclinical Division, Vimta Labs Limited, Hyderabad, Telangana, India
}

Received: 28 September 2021

Accepted: 22 October 2021

\section{*Correspondence:}

Dr. Shefali Thanawala,

Email: shefali.thanawala@inventiahealthcare.com

Copyright: (C) the author(s), publisher and licensee Medip Academy. This is an open-access article distributed under the terms of the Creative Commons Attribution Non-Commercial License, which permits unrestricted non-commercial use, distribution, and reproduction in any medium, provided the original work is properly cited.

\begin{abstract}
Background: Objective of this study was to evaluate anti-inflammatory properties of a novel standardized Boswellia serrata extract-bsRx (developed using natural excipients and designed to have specific ratio of its major actives, viz. AKBA and BBA) in dextran sodium sulfate (DSS)-induced IBD model in BALB/c mice.

Methods: Animals (BALB/c mice) in control (CL) group were administered vehicle; DSS-induced colitis group (DSS group), $2.5 \%$ DSS; and Boswellia serrata group (BS group) received DSS, for inducing colitis, together with a novel standardized extract of Boswellia serrata $(41 \mathrm{mg} / \mathrm{kg}, 4.1 \mathrm{mg} / \mathrm{ml}$ solution in distilled water) for 10 days. Reference group (SS group) received DSS with sulfasalazine $(30 \mathrm{mg} / \mathrm{kg}, 3.0 \mathrm{mg} / \mathrm{ml}$ suspension in distilled water) for 10 days. Clinical assessment for disease activity index (DAI), histopathological examination and hematological assessments were performed.

Results: Treatment with Boswellia serrata showed significant reduction in the DAI score on day 10 compared to the DSS group (2.49 \pm 0.93 versus $3.63 \pm 0.55, \mathrm{p} \leq 0.05)$. Body weight $(18.54 \pm 2.21 \mathrm{gm}$ versus $17.05 \pm 3.53 \mathrm{gm})$ and colon length $(6.8 \pm 0.9 \mathrm{~cm}$ versus $7.6 \pm 0.6 \mathrm{~cm}, \mathrm{p} \leq 0.05)$ also improved in the BS group compared to DSS group, respectively.

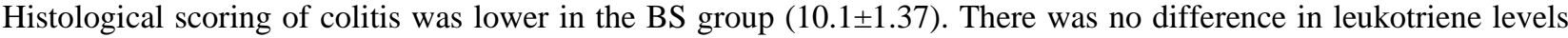
between groups $(\mathrm{p}>0.05)$.

Conclusions: Treatment with novel Boswellia serrata extract improved colon length, DAI and histological scoring index in DSS-induced colitis in IBD mice models. Our results indicate the promising potential of novel Boswellia extract in IBD and gut health management.
\end{abstract}

Keywords: Colitis, Boswellia serrata, Boswellic acids, IBD, Anti-inflammatory, Gut health, AKBA

\section{INTRODUCTION}

Inflammatory bowel disease (IBD) imposes a significant health and economic burden on communities worldwide and substantially compromises the patients' quality of life. ${ }^{1}$ The estimated number of cases of IBD is 6.8 million globally, and the burden is estimated to rise considerably. ${ }^{1}$ It is characterized by non-infectious chronic inflammation of the gastrointestinal tract that includes ulcerative colitis (UC) and Crohn's disease (CD). Chronic diarrhea, abdominal pain, rectal bleeding, weight loss, and shortening of the colon are common symptoms of IBD. Pathophysiology of IBD broadly shares a multifactorial etiology where an interplay of genetic and environmental factors triggering an array of immune responses has a pivotal role to play. ${ }^{2,3}$ Increase in the number of reactive oxygen species and different proinflammatory mediators like nitrogen metabolites, eicosanoids, chemokines and cytokines actively contribute to the pathogenic cascade of inflammatory responses in the gut. ${ }^{2,3}$ 
Current IBD therapies include classic anti-inflammatory drugs such as 5-aminosalicylic acid (5-ASA), sulfasalazine; immunosuppressants like azathioprine, corticosteroids; and biological therapy with anti-tumor necrosis factor (TNF) agents. ${ }^{4}$ However, despite their better efficacy, the frequency and severity of adverse effects, inconvenient dosing regimen, and their high costs limit long-term use. Moreover, single-target therapy may not be successful owing to the pathogenic heterogeneity of IBD. Given these limitations, developing alternative treatment options with multiple therapeutic targets could result in combining efficacy, convenient dosing and fewer side-effects. Thus, use of complementary and alternative medicine (CAM) has emerged as a novel approach for managing gastrointestinal diseases and for improving and maintaining gut health. In fact, studies have reported that almost half of the patients with IBD are currently using complementary therapies or have taken them in the past. ${ }^{5}$ Among various complementary therapies available, botanical products hold potential relevance as they present with a long history of traditional usage and are composed of multiple phytoactives, which can concurrently target several inflammatory response pathways thus, providing a more comprehensive approach in managing the disease.

Boswellia serrata is a traditional plant indigenous to India. ${ }^{6-8}$ The anti-inflammatory and analgesic activities from the oleogum resin of Boswellia have been recognized since the ancient times and it is traditionally used in the management of diseases like bronchial asthma, osteoarthritis, rheumatoid arthritis, UC, and CD. ${ }^{9}$ Along with anti-inflammatory properties, its antioxidant, antiulcer, hepatoprotective, wound healing, analgesic and anticancer properties are also being evaluated to navigate treatment and prevention. ${ }^{7-10}$ Lately, several clinical trials on the anti-inflammatory responses of the herb have been reported. ${ }^{11}$ However, there has been little progress in terms of exploring the therapeutic potential of Boswellia serrata in the gastrointestinal conditions such as IBD and ulcerative colitis, and its role in the management of gut health. Here we present a study that was conducted to establish the multifaceted therapeutic properties of a novel standardized Boswellia serrata extract - bsRx (developed using natural excipients and designed to have specific ratio of its major actives, viz. AKBA and BBA) in dextran sodium sulfate (DSS)-induced IBD model in BALB/c mice.

\section{METHODS}

\section{Animals and ethics}

A total of $50 \mathrm{BALB} / \mathrm{c}$ mice (Mus musculus) of both genders, aged between 7 to 10 weeks, weighing between 18 and $26 \mathrm{~g}$ were used in this study. Animals were selected based on the proposed design of randomization, and the rest of the animals were returned to the animal facility without any investigation. Study animals were maintained at $20.2-24.3{ }^{\circ} \mathrm{C}$ at $48-67 \%$ relative humidity in a light and dark cycle of 12 hours. Animals were housed individually in autoclaved polysulfone cages with stainless steel top grill that had a provision for holding pellet food and drinking water in a polycarbonate bottle with stainless steel sipper tube. Autoclaved corn cob was used as the bedding material. Cages and water bottles were changed at least 2 times a week. Bedding material was analyzed routinely for any microbial and chemical contaminants.

The study was performed as per the Organisation for Economic Cooperation and Development (OECD) principles of good laboratory practice (GLP) ENV/MC/CHEM (98) 17, Environment Directorate, Paris, 1998. This study also met the requirements of the US FDA principles of GLP for testing of chemicals as specified by CFR 21 - part 58, revised 01 April 2017. The OECD-GLP by the national GLP compliance monitoring authority (NGCMA), department of science and technology, government of India, certified the testing facility for compliance to GLP and by international association for assessment and accreditation of laboratory animal care (AAALAC) for standard lab animal care. All procedures related to animal experimentation were performed as per the recommendations of 'guide for care and use of laboratory animals' and the 'committee for the purpose of control and supervision of experiments on animals' (CPCSEA) guidelines. Ethical practices laid down in the CPCSEA guidelines for animal care were followed. The protocol number was VLL/1218/NG/P002.

\section{Study design}

All animals were acclimatized for five days. They were observed once daily (at least) for clinical signs, and twice daily for any mortality/morbidity. Their body weights were recorded on the day of randomization. Forty animals (20 of each gender) were selected for the study and randomized by a zig-zag method based on body weight. The animals were then divided into four groups of 10 animals each (05 mice/gender/group). Those in the control (CL) group were treated with vehicle; DSS-induced colitis group (DSS group) received 2.5\% DSS and the Boswellia serrata group (BS group) received DSS for inducing colitis, together with a novel standardized extract of Boswellia serrata containing acetyl-11-keto- $\beta$-boswellic acid (AKBA) and beta boswellic acid (BBA) $(41 \mathrm{mg} / \mathrm{kg}$, $4.1 \mathrm{mg} / \mathrm{ml}$ solution distilled water) for 10 days. The fourth group being the reference group (SS group) received DSS together with sulfasalazine $(30 \mathrm{mg} / \mathrm{kg}, 3.0 \mathrm{mg} / \mathrm{ml}$ suspension in distilled water) for 10 days. Test samples of standardized Boswellia serrata extract were obtained as an off-white colored hygroscopic powder from Inventia Healthcare Ltd., India. The samples and reference products were stable at room temperature and analyzed as per the certificate of analysis provided by the vendor before the study.

\section{Induction of colitis}

Owing to ease of use and potentially short turnaround time for obtaining results, DSS is one of the most commonly 
used chemical agents for inducing colitis in animal models. To induce colitis, DSS was administered to the animals in drinking water for 10 days $(2.5 \%$; $36 \mathrm{KDa}$ to 50 KDa molecular weight) according to the weight and the type of strain used in this study. The animals were observed once daily (minimum) throughout the study for signs of colitis, namely, dullness, anorexia, hunched back posture, abnormal gait, morbidity, and mortality.

\section{Disease activity index}

The disease activity index (DAI) was calculated as an arithmetic average of graded scores for clinical signs (Table 1). All animals were monitored once daily for clinical signs of colitis, mortality, and morbidity throughout the study period. The DAI was calculated as the sum of combined scores of weight loss, stool consistency and bleeding, divided by 3 . This method of scoring was shown to correlate well with more specific measures of inflammation in experimental models of IBD. ${ }^{12}$ Onset of colitis was assessed for up to 10 days.

\section{Colon length, body weight and histological colitis score}

All animals were euthanized by $\mathrm{CO}_{2}$ overdose 24 hours after the last treatment day i.e. day 11 . Body weight and colon length were measured and samples were prepared for histopathological examination. Microscopic and macroscopic analysis was performed for histological samples. Gross lesions were evaluated by a scoring system and classified according to a criteria modified from Morris et al. ${ }^{13}$ The isolated distal portions of the colon from all animals were preserved in $10 \%$ neutral buffered formalin. The colon was then processed, embedded and sections were cut at 3-5 $\mu$, and placed on grease-free slides and stained with hematoxylin and eosin for histopathological evaluation. The microscopic changes in the colonic mucosa were scored for crypts and inflammation and were graded (Table 1). Any damage caused was evaluated per criteria by Millar et al. ${ }^{14-16}$

\section{Leukotriene estimation}

Retroorbital blood samples from all animals were obtained under mild anesthesia using $2 \% \mathrm{v} / \mathrm{v}$ isoflurane on day 10 for leukotriene estimation and was mixed with anticoagulant, $10 \%$ dipotassium ethylenediaminetetraacetic acid $\left(\mathrm{K}_{2}\right.$ EDTA) and centrifuged at $3500 \mathrm{rpm}$ for 10 min under refrigeration $\left(2-8^{\circ} \mathrm{C}\right)$. All plasma samples were stored at $-70^{\circ} \mathrm{C}$ until enzyme-linked immunosorbent assay (ELISA) was performed for estimating leukotriene B4 (LTB4).

An ELISA kit (Biocodon Technologies Rat Leukotriene B4 ELISA kit) measured the LTB4 content in cell-free culture supernatants following the manufacturer's instructions. The assay utilized competitive antigenantibody binding principle. Following the substrate reaction, the absorbance of the developed color was measured at $450 \mathrm{~nm}$ in a microplate reader (Model, Maker). The amount of LTB4 present in the supernatants was quantified by comparing the optical density values with a standard curve plotted against the known concentrations of the analyte.

\section{Statistical analysis}

All data were presented as mean \pm SD and were obtained by calculating the group mean and standard deviation using statistical package for the social sciences (SPSS) ${ }^{\circledR}$ statistical software, United States of America (USA). Observations were subject to analysis of variance (ANOVA) at 95\% $(\mathrm{p} \leq 0.05)$ and $99 \%(\mathrm{p} \leq 0.01)$ confidence intervals to prove its statistical significance. The control group was compared to the DSS and the DSS group was compared to the treated groups.

Table 1: Scoring for disease activity index and histological scoring index.

\begin{tabular}{|c|c|c|c|c|c|c|c|}
\hline \multirow[b]{2}{*}{ Score } & \multicolumn{3}{|c|}{ Disease activity index } & \multicolumn{4}{|l|}{ Histological scoring index } \\
\hline & $\begin{array}{l}\text { Weight } \\
\text { loss } \\
(\%)\end{array}$ & $\begin{array}{l}\text { Stool } \\
\text { consistency }\end{array}$ & $\begin{array}{l}\text { Faecal } \\
\text { occult blood }\end{array}$ & Crypt & $\begin{array}{l}\text { Crypt } \\
(\%)\end{array}$ & Inflammation & $\begin{array}{l}\text { Extent of } \\
\text { damage } \\
(\%)\end{array}$ \\
\hline $\mathbf{0}$ & 0 & Normal & Normal & Crypt intact & - & Normal & - \\
\hline 1 & 1 to $<5$ & - & - & Loss of $1 / 3$ crypt & $1-25$ & $\begin{array}{l}\text { Focal } \\
\text { inflammatory cell } \\
\text { infiltrate }\end{array}$ & $1-25$ \\
\hline 2 & $\begin{array}{l}5 \text { to } \\
<10\end{array}$ & Loose & Positive** & Loss of $2 / 3$ crypt & $26-50$ & $\begin{array}{l}\text { Inflammatory cell } \\
\text { infiltrate, gland } \\
\text { drop out and crypt } \\
\text { abscess }\end{array}$ & $26-50$ \\
\hline 3 & $\begin{array}{l}10 \text { to } \\
<20\end{array}$ & - & - & $\begin{array}{l}\text { Loss of entire crypt with } \\
\text { intact surface epithelium }\end{array}$ & $51-75$ & $\begin{array}{l}\text { Mucosal } \\
\text { ulceration }\end{array}$ & $51-75$ \\
\hline 4 & $>20$ & Diarrhea & $\begin{array}{l}\text { Gross } \\
\text { bleeding** }\end{array}$ & $\begin{array}{l}\text { Loss of entire crypt with } \\
\text { erosion of surface } \\
\text { epithelium }\end{array}$ & $76-100$ & - & $76-100$ \\
\hline
\end{tabular}

*Presence of occult blood in stool, **profuse bleeding from the rectum 


\section{RESULTS}

\section{Clinical observations}

The routine cage observations were done once daily throughout the study for signs of colitis (dullness, anorexia, hunched back posture, and abnormal gait), morbidity, and mortality. Dullness and hunchback posture were observed from day 04 of the study until the end of study (day 10) in all the study groups.

\section{Colon length and body weight}

The colon length reduced in the DSS group compared to the control group $(6.8 \pm 0.9 \mathrm{~cm}$ versus $8.8 \pm 1.1 \mathrm{~cm}, \mathrm{p} \leq 0.01)$ whereas mice from the BS group showed longer colon compared to those of the DSS group $(6.8 \pm 0.9 \mathrm{~cm}$ versus $7.6 \pm 0.6 \mathrm{~cm}, \mathrm{p} \leq 0.05)$. Weight loss was observed in all groups compared to the control group. However, body weight on day 10 for the DSS group was lower than the control group $(17.05 \pm 3.53 \mathrm{gm}$ versus $21.29 \pm 2.25 \mathrm{gm}$, $\mathrm{p} \leq 0.05)$ whereas that of the BS group improved compared to DSS group $(18.54 \pm 2.21 \mathrm{gm}$ versus $17.05 \pm 3.53 \mathrm{gm})$. Figures 1 and 2 show the effects of Boswellia serrata on colon length and body weight when used concomitantly with DSS, respectively.

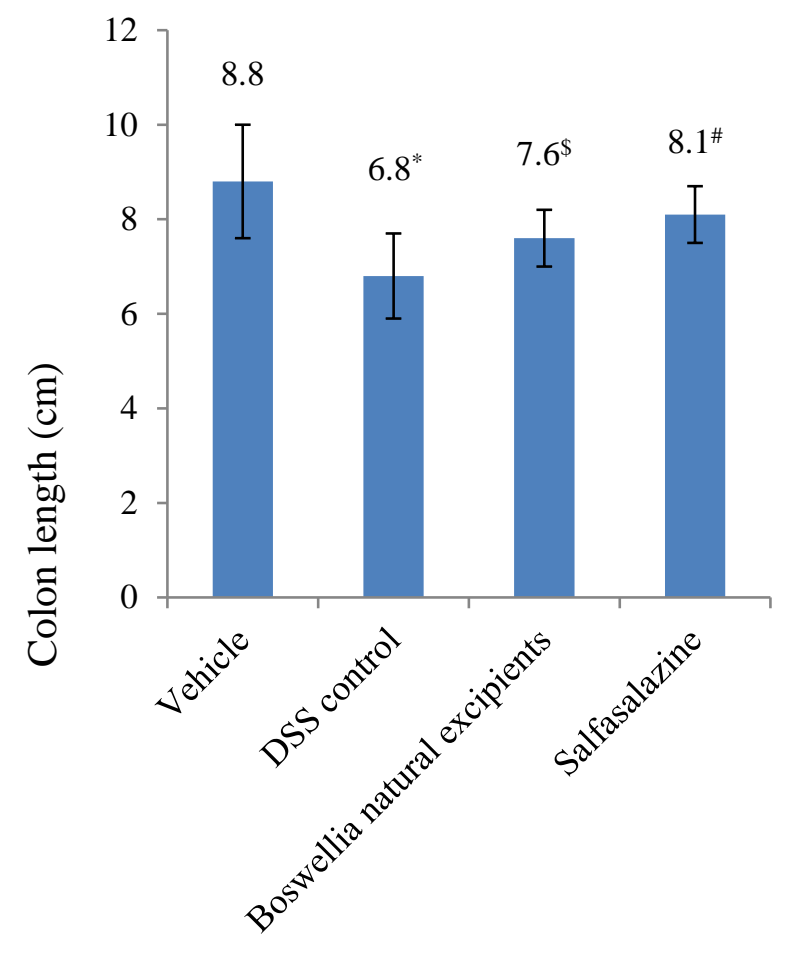

Figure 1: A comparative graph showing effect of standardized extract of Boswellia serrata on colon length at day 10.

*Significant low at $p \leq 0.01$ versus vehicle control; \#significant high at $p \leq 0.01$ versus DSS control; \$significant high at $\mathrm{p} \leq 0.05$ versus DSS control
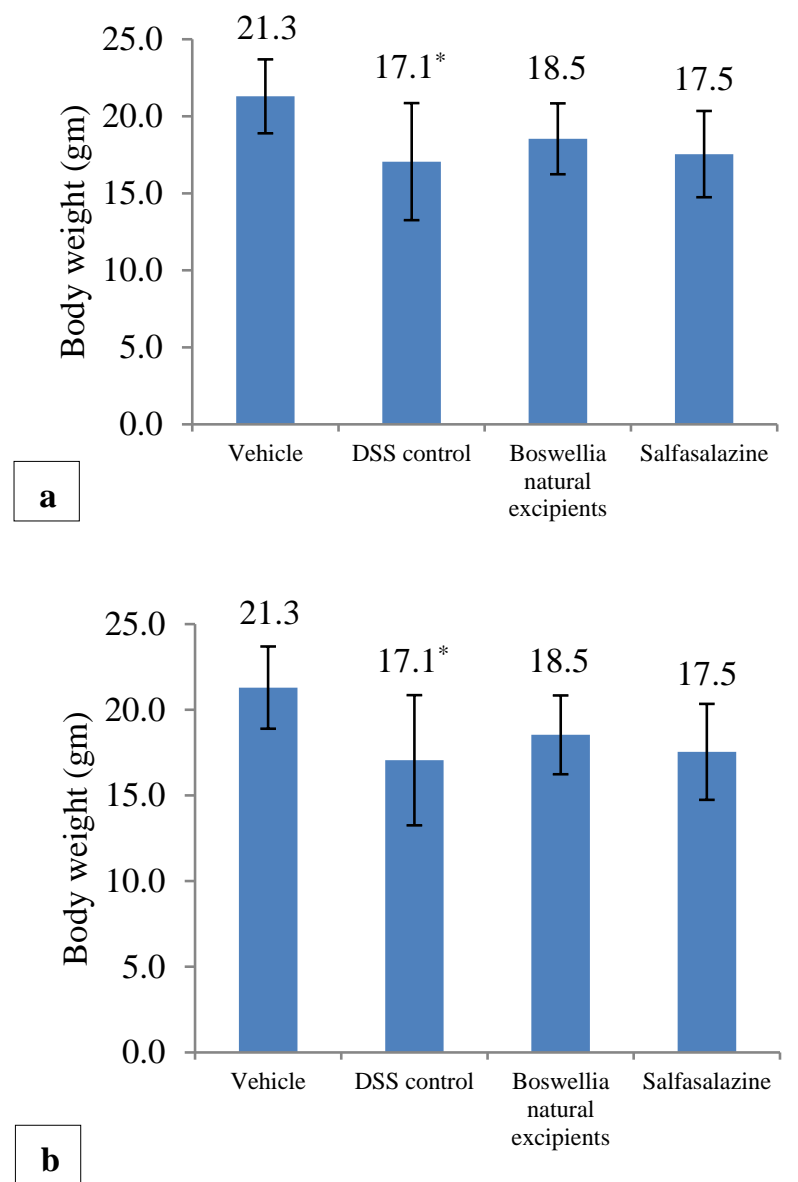

Figure 2: (a) A comparative graph showing effect of standardized extract of Boswellia serrata on body weight at day 10, and (b) mortality in percentage for various groups.

*Significant low at $\mathrm{p} \leq 0.05$ versus vehicle control.

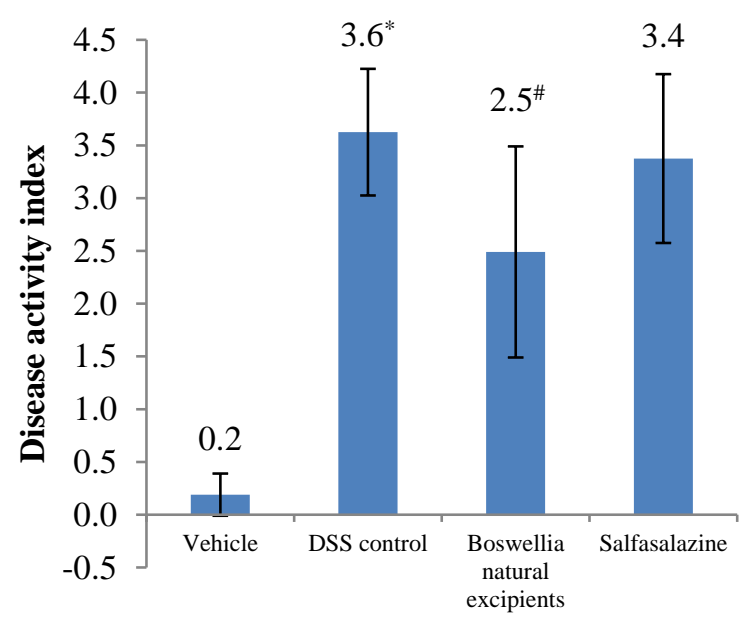

Figure 3: A comparative graph showing effect of standardized extract of Boswellia serrata on the disease activity index (DAI) at day 10.

*Significant high at $\mathrm{p} \leq 0.01$ versus vehicle control; \#significant low at $\mathrm{p} \leq 0.05$ versus DSS control 


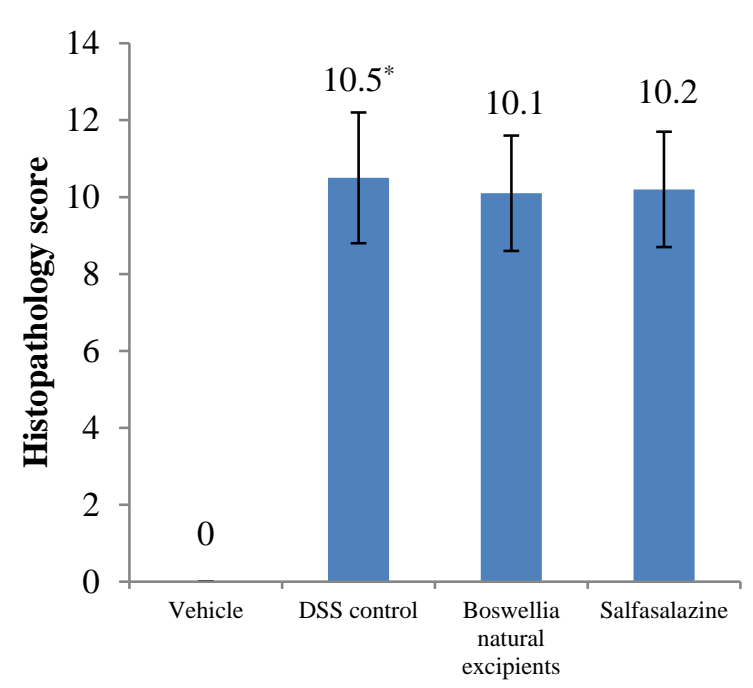

Figure 4: A comparative graph showing effect of standardized extract of Boswellia serrata on histopathology score at day 10.

*Significant high at $p \leq 0.01$ versus vehicle control

\section{Disease activity index}

The DSS group showed an onset of colitis with signs of perianal bleeding, weight loss, and loose stools from day 04 of the study period whereas the BS group showed no mortality or morbidity (Figure 2). On day 10, one-fifth of the group population showed mortality in both DSS and SS groups. At end of study, the DAI for the DSS group was significantly higher $(3.63 \pm 0.55$ versus $0.19 \pm 0.22$, $\mathrm{p} \leq 0.01$ ) than the control group indicating presence of active colitis in the DSS group of the study. Whereas, the BS group showed a significant reduction in the DAI score on day 10 compared to the DSS group $(2.49 \pm 0.93$ versus $3.63 \pm 0.55, \mathrm{p} \leq 0.05)$. Figure 3 shows the effect of Boswellia serrata on DAI when used concomitantly with DSS.

\section{Histological scoring of colitis}

The colonic tissues were normal in the control group and damaged in the DSS groups. Histological scoring of colitis for the DSS group was significantly higher than that of the control group $(10.5 \pm 1.63$ versus $0.00, p \leq 0.01)$. On the other hand, the scoring slowed a slight reduction in the BS group (10.1 \pm 1.37$)$. Figure 4 shows the positive effects of treatment with Boswellia serrata on histological scoring. Figure 5 shows characteristic features of colitis in study groups.

\section{Leukotriene concentration}

Presence of LTB4 in the mouse plasma was estimated using ELISA in all mice who survived. Low concentrations (below $1 \mathrm{ng} / \mathrm{ml}$ ) of LTB4 were detected in all groups. There was no difference in the leukotriene levels between groups $(\mathrm{p}>0.05)$.

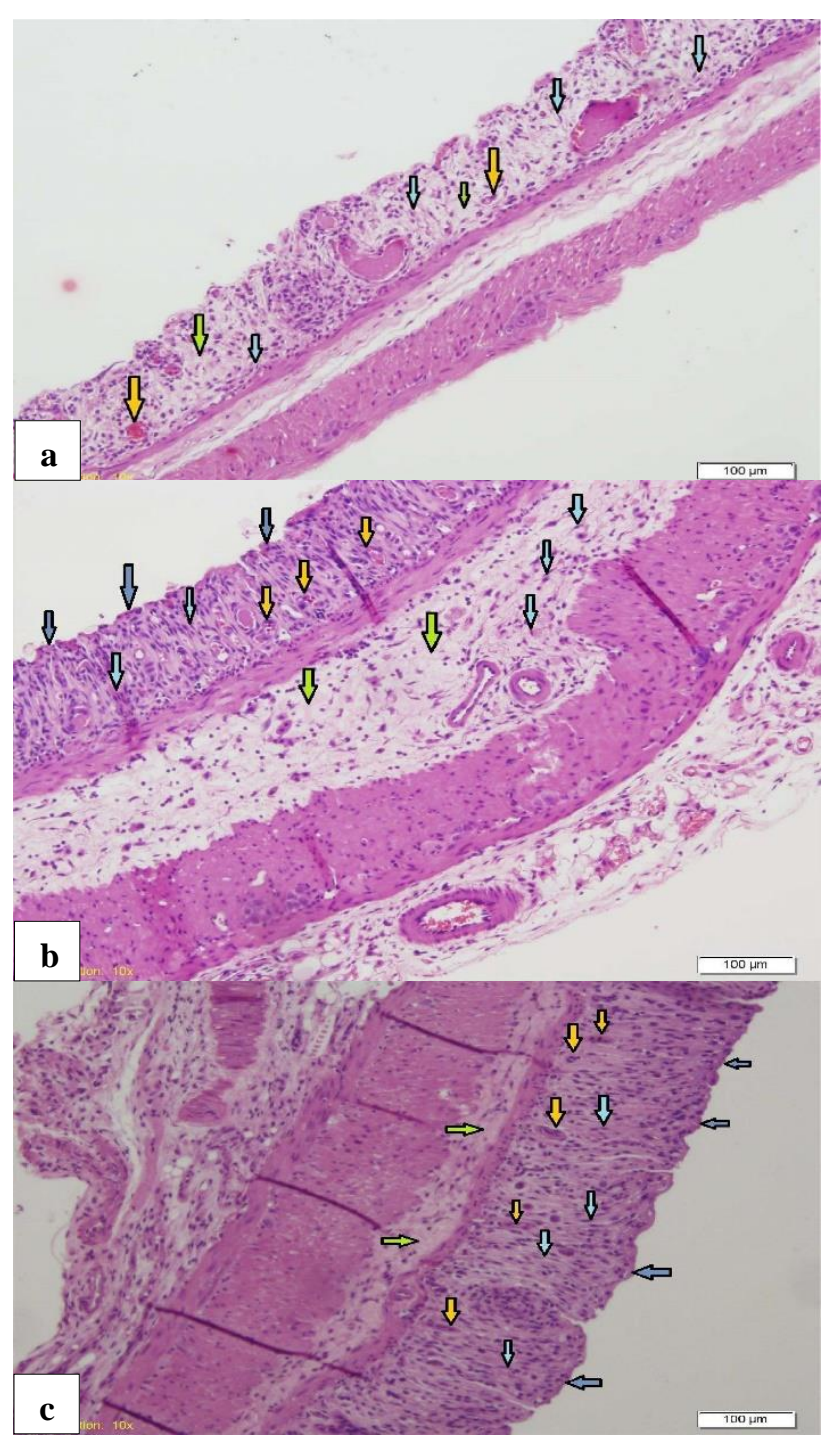

Figure 5: Histopathological changes in colon of the animal from (a) DSS control group (b) Boswellia natural excipients group and (c) Salfasalazine group. The arrows in yellow, green, blue and grey indicate neovascularization, edema, fibroblast proliferation and epithelial cell regeneration, respectively.

\section{DISCUSSION}

Present study evaluated the preventive potential of novel Boswellia serrata extract in mice model of DSS-induced UC. Treatment with novel standardized Boswellia extract inhibited the adverse impact of DSS on colon length, body weight, histopathological scores and reduced the DAI. Hence, our study product-Boswellia serrata extract has a promising potential for use in reducing the severity of UC.

Boswellia serrata has been used for centuries as a remedy for many health problems in the traditional ayurvedic medicine system in India. Boswellic acids have also been used as anti-inflammatory agents in several small clinical trials, however, relatively not much is known about the mechanisms that underlie their anti-inflammatory actions 
in vivo. ${ }^{17-20}$ Boswellia extract also exhibits antioxidant actions that reportedly produced $25 \%$ reduction in the number of reactive oxygen species induced by $\mathrm{H}_{2} \mathrm{O}_{2}$ in an in vitro study that used Caco- 2 cell lines. ${ }^{21}$ It also inhibits 5-lipoxygenase, a key enzyme for the production of leukotrienes in the body. ${ }^{10} \mathrm{AKBA}$ is a potent inhibitor of leukotriene synthesis and directly acts on 5-lipoxygenase. ${ }^{6}$ Boswellia serrata also reportedly down-regulates TNF- $\alpha$, IL-1 $\beta$, and IL-6 mRNA expression and inhibits production of nitric oxide, leukocyte elastase, cytokines (ILs and TNF- $\alpha$ ) and the complement system. ${ }^{22,23}$ Inhibition of TNF- $\alpha$ and its signaling pathways has been recognized as a highly successful strategy for the treatment of IBD. ${ }^{24}$ Collectively, these findings provide molecular basis for the anti-inflammatory properties of Boswellia serrata extract, and therefore, we hypothesize it to be effective in preventing inflammatory cascade in mice models of UC. The active ingredient of this extract is AKBA which is approximately 2-3\% in higher grade Boswellia serrata extracts. AKBA inhibits the P-selectin-mediated recruitment of inflammatory cells protecting intestinal epithelial barrier from inflammatory damage suggesting it to be an effective alternative for management of gut health. ${ }^{17} \mathrm{BBA}$ is another major boswellic acid present in the highest percentage in the oleo gum resin of Boswellia. Similar to AKBA, BBA also shows prominent antiinflammatory activity. ${ }^{25}$ In both in vitro and in vivo research studies, BBA has been shown to inhibit proinflammatory markers ${ }^{26}$ such as microsomal prostaglandin E2 synthase (mPGES-1), which plays a critical role in the gut motility dysfunction ${ }^{27}$ and cathepsin $\mathrm{G}$ (catG) that is an essential signaling molecule in gastrointestinal physiology. Dysregulation of catG elicits structural and functional changes in the mucosal barrier and participate in inflammation. Studies have shown that catG increases in IBD. ${ }^{28}$

In the present study, the colon lengths and body weights of mice improved when treated with Boswellia serrata extract compared to the DSS group indicates its preventive action when concomitantly administered with DSS. Previous study by Latella et al. showed a significant increase in colon length with AKBA. ${ }^{29}$ However, the extract was not able to prevent weight loss compared to the control group, indicating that it does not reverse the effects on weight loss. A similar observation was also reported by Pawel et al where Boswellia serrata extract was earlier proven to possess protective properties and improve DAI of chemically-induced colitis in animal models. ${ }^{17,29,30}$ Krieglstien et al proved that treatment with $20 \%$ AKBA resulted in up to $90 \%$ decrease in rolling and $98 \%$ decrease in adherent leucocytes in the ileitis model. ${ }^{31} \mathrm{~A}$ remarkable decrease in the DAI score and improvement in the histopathological score could be due to the protective properties of AKBA on the colonic mucosa.

Treatment with the novel Boswellia extract (containing specific ratio of AKBA and BBA) in our study showed dose-dependent decrease in DAI, and significant attenuation of the tissue injury scores that might be attributed to specific ratios of $\mathrm{AKBA}$ and $\mathrm{BBA}$ in the test product. Interestingly, the suppression of intensity of inflammation and reduced disease activity exhibited in mice receiving the test product in our study was comparable to those attained by sulfasalazine, an agent widely used for the treatment of IBD. ${ }^{8,9,32-35}$ Many studies also proved effectiveness of boswellic acids in UC compared to the effect of sulfasalazine using in vivo models and clinical studies. ${ }^{36-40}$ Both Boswellia extract and sulfasalazine in this study also showed similar pattern of results indicating anti-inflammatory potential of the standardized novel Boswellia extract (with specific ratio of AKBA and BBA) in mice models of UC thus, proving that the test product reduces macroscopic and microscopic inflammatory response in mice models.

The content of AKBA and BBA in commercially available products vary greatly; however, the test product is standardized to a specific ratio of AKBA and BBA in order to consistently provide significant therapeutic benefits observed in this study. In addition, the test product is developed using natural excipients further contributing to the long-term safety of the product.

The present study focuses on proving the effectiveness of the unique concentration combination of AKBA and BBA in the present Boswellia extract product. Due to bioavailability limitations, previous products of Boswellia extract have been unable to provide higher efficacy in in vivo models and clinical studies. The present Boswellia extract was able to improve the colon length, DAI and histological scoring index in DSS induced mice models of UC which had a direct and positive impact on mortality rate. Thus, proving our hypothesis and providing evidence of anti-inflammatory action of the test product. However, in the present study, the test product was unable to achieve a reduced leukotriene level and hence this parameter should be explored further and all the results should be substantiated with clinical trials.

\section{CONCLUSION}

In this experimental study, treatment with novel Boswellia serratta extract improved colon length, DAI, and histological scoring index in DSS induced mice models of UC. In line with the published literature on Boswellia serrata, our results support the anti-inflammatory action of novel Boswellia extract developed using specific ratio of AKBA and BBA along with natural excipients in mice. Our results show a promising role of the novel Boswellia extract in the management of IBD and gut health; however, clinical trials are required to substantiate these results further and confirm the role of this novel Boswellia serrata extract in the management of gut health.

\section{ACKNOWLEDGEMENTS}

Authors would like to thank CBCC Global Research for providing medical writing and editorial assistance in development of this manuscript. 
Funding: The study was funded by Inventia Healthcare Ltd.

Conflict of interest: None declared

Ethical approval: The study was approved by the Institutional Ethics Committee

\section{REFERENCES}

1. Alatab S, Sepanlou SG, Ikuta K, Vahedi H, Bisignano $\mathrm{C}$, Safiri S, et al. The global, regional, and national burden of inflammatory bowel disease in 195 countries and territories, 1990-2017: a systematic analysis for the Global Burden of Disease Study 2017. Lancet Gastroenterol Hepatol. 2020;5(1):17-30.

2. Loddo I, Romano C. Inflammatory bowel disease: genetics, epigenetics, and pathogenesis. Front Immunol. 2015;6:551.

3. Dragasevic S, Stankovic B, Milosavljevic T, SokicMilutinovic A, Lukic S, Alempijevic T, et al. Genetic and environmental factors significant for the presentation and development of inflammatory bowel disease. Eur J Gastroenterol Hepatol. 2017;29(8):90915 .

4. Leitner GC, Vogelsang H. Pharmacological-and nonpharmacological therapeutic approaches in inflammatory bowel disease in adults. World $\mathbf{J}$ Gastrointest Pharmacol Ther. 2016;7(1):5-20.

5. Weizman AV, Ahn E, Thanabalan R, Leung W, Croitoru K, Silverberg MS, et al. Characterisation of complementary and alternative medicine use and its impact on medication adherence in inflammatory bowel disease. Aliment Pharmacol Ther. 2012;35(3):342-9.

6. Hartmann RM, Fillmann HS, Martins MI, Meurer L, Marroni NP. Boswellia serrata has beneficial antiinflammatory and antioxidant properties in a model of experimental colitis. Phytother Res. 2014;28(9):13928.

7. Beghelli D, Isani G, Roncada P, Andreani G, Bistoni $\mathrm{O}$, Bertocchi $\mathrm{M}$, et al. Antioxidant and ex vivo immune system regulatory properties of Boswellia serrata extracts. Oxid Med Cell Longev. 2017;7468064.

8. Bertocchi M, Isani G, Medici F, Andreani G, Tubon Usca I, Roncada P, et al. Anti-inflammatory activity of Boswellia serrata extracts: an in vitro study on porcine aortic endothelial cells. Oxid Med Cell Longev. 2018;2504305.

9. Ammon HP. Boswellic acids and their role in chronic inflammatory diseases. Adv Exp Med Biol. 2016;928:291-327.

10. Suva MA, Kheni DB, Sureja VP. Aflapin ${ }^{\circledR}$ : A novel and selective 5-lipoxygenase inhibitor for arthritis management. Indian J Pain. 2018;32(1):16-23.

11. Yu G, Xiang W, Zhang T, Zeng L, Yang K, Li J. Effectiveness of Boswellia and Boswellia extract for osteoarthritis patients: a systematic review and metaanalysis. BMC Complement Med Ther. 2020;20(1):225

12. Murthy SN, Cooper HS, Shim H, Shah RS, Ibrahim SA, Sedergran DJ. Treatment of dextran sulfate sodium-induced murine colitis by intracolonic cyclosporin. Dig Dis Sci. 1993;38(9):1722-34.

13. Morris GP, Beck PL, Herridge MS, Depew WT, Szewczuk MR, Wallace JL. Hapten-induced model of chronic inflammation and ulceration in the rat colon. Gastroenterology. 1989;96(3):795-803.

14. Millar AD, Rampton DS, Chander CL, Claxson AW, Blades S, Coumbe A, et al. Evaluating the antioxidant potential of new treatments for inflammatory bowel disease using a rat model of colitis. Gut. 1996;39(3):407-15.

15. Park YH, Kim N, Shim YK, Choi YJ, Nam RH, Choi $\mathrm{YJ}$, et al. Adequate dextran sodium sulfate-induced colitis model in mice and effective outcome measurement method. J Cancer Prev. 2015;20(4):2607.

16. Rajesh B, Fleming A, Ramchandra R, Rajesh S, Shilpesh D. Effect of Tribulus terrestris against inflammatory bowel disease. Int $\mathrm{J}$ Vet Sci. 2013;2(4):143-50.

17. Anthoni C, Laukoetter MG, Rijcken E, Vowinkel T, Mennigen R, Müller S, et al. Mechanisms underlying the anti-inflammatory actions of boswellic acid derivatives in experimental colitis. Am J Physiol Gastrointest Liver Physiol. 2006;290(6):1131-7.

18. Riva A, Giacomelli L, Togni S, Franceschi F, Eggenhoffner R, Zuccarini MC, et al. Oral administration of a lecithin-based delivery form of boswellic acids (Casperome $\left.{ }^{\circledR}\right)$ for the prevention of symptoms of irritable bowel syndrome: a randomized clinical study. Minerva Gastroenterol Dietol. 2019;65(1):30-5.

19. Notarnicola A, Maccagnano G, Moretti L, Pesce V, Tafuri S, Fiore A, et al. Methylsulfonylmethane and boswellic acids versus glucosamine sulfate in the treatment of knee arthritis: Randomized trial. Int $\mathbf{J}$ Immunopathol Pharmacol. 2016;29(1):140-6.

20. Riva A, Morazzoni P, Artaria C, Allegrini P, Meins J, Savio D, et al. A single-dose, randomized, cross-over, two-way, open-label study for comparing the absorption of boswellic acids and its lecithin formulation. Phytomedicine. 2016;23(12):1375-82.

21. Governa P, Marchi M, Cocetta V, De Leo B, Saunders PTK, Catanzaro D, et al. Effects of Boswellia Serrata Roxb. and Curcuma longa L. in an in vitro intestinal inflammation model using immune cells and Caco-2. Pharmaceuticals (Basel). 2018;11(4):126.

22. Gayathri B, Manjula N, Vinaykumar KS, Lakshmi BS, Balakrishnan A. Pure compound from Boswellia serrata extract exhibits anti-inflammatory property in human PBMCs and mouse macrophages through inhibition of TNF $\alpha$, IL-1 $\beta$, NO and MAP kinases. Int Immunopharmacol. 2007;7(4):473-82.

23. Kapil A, Moza N. Anticomplementary activity of boswellic acids - an inhibitor of C3-convertase of the classical complement pathway. Int J Immunopharmacol. 1992;14(7):1139-43.

24. Song YN, Zheng P. Efficacy and safety of tumor necrosis factor- $\alpha$ blockers for ulcerative colitis: A systematic review and meta-analysis of published 
randomized controlled trials. J Food Drug Anal. 2015;23(1):1-10.

25. Sarkate A, Dhaneshwar SS. Investigation of mitigating effect of colon-specific prodrugs of boswellic acid on 2, 4, 6-trinitrobenzene sulfonic acidinduced colitis in Wistar rats: Design, kinetics and biological evaluation. World J Gastroenterol. 2017;23(7):1147-62.

26. Hüsch J, Gerbeth K, Fricker G, Setzer C, Zirkel J, Rebmann $\mathrm{H}$, et al. Effect of phospholipid-based formulations of Boswellia serrata extract on the solubility, permeability, and absorption of the individual boswellic acid constituents present. J Nat Prod. 2012;75(10):1675-82.

27. Lin YM, Fu Y, Hegde S, Tang Y, Radhakrishnan R, Shi XZ. Microsomal Prostaglandin E Synthase-1 Plays a Critical Role in Long-term Motility Dysfunction after Bowel Obstruction. Sci Rep. 2018;8(1):8831.

28. Jablaoui A, Kriaa A, Mkaouar H, Akermi N, Soussou $\mathrm{S}$, Wysocka M, et al. Fecal serine protease profiling in inflammatory bowel diseases. Front Cell Infect Microbiol. 2020;10:21.

29. Latella G, Sferra R, Vetuschi A, Zanninelli G, D'Angelo A, Catitti V, et al. Prevention of colonic fibrosis by Boswellia and Scutellaria extracts in rats with colitis induced by 2, 4, 5-trinitrobenzene sulphonic acid. Eur J Clin Invest. 2008;38(6):410-20.

30. Kiela PR, Midura AJ, Kuscuoglu N, Jolad SD, Sólyom AM, Besselsen DG, et al. Effects of Boswellia serrata in mouse models of chemically induced colitis. Am J Physiol Gastrointest Liver Physiol. 2005;288(4):798808 .

31. Krieglstein CF, Anthoni C, Rijcken EJ, Laukötter M, Spiegel HU, Boden SE, et al. Acetyl-11-keto- $\beta$ boswellic acid, a constituent of a herbal medicine from Boswellia serrata resin, attenuates experimental ileitis. Int J Colorectal Dis. 2001;16(2):88-95.

32. Khanna R, Marshall JK. Sulfasalazine and 5Aminosalicylates for Ulcerative Colitis. In: Baumgart DC, editor. Crohn's Disease and Ulcerative Colitis. 2017;389-97.

33. Alluri VK, Kundimi S, Sengupta K, Golakoti T, Kilari EK. An Anti-Inflammatory Composition of Boswellia serrata Resin Extracts Alleviates Pain and Protects Cartilage in Monoiodoacetate-Induced Osteoarthritis in Rats. Evid Based Complement Alternat Med. 2020;7381625.

34. Krüger P, Daneshfar R, Eckert GP, Klein J, Volmer DA, Bahr U, et al. Metabolism of boswellic acids in vitro and in vivo. Drug Metab Dispos. 2008;36(6):1135-42.

35. Roy NK, Parama D, Banik K, Bordoloi D, Devi AK, Thakur KK, et al. An update on pharmacological potential of boswellic acids against chronic diseases. Int J Mol Sci. 2019;20(17):4101.

36. Qurishi Y, Hamid A, Zargar MA, Singh SK, Saxena AK. Potential role of natural molecules in health and disease: Importance of boswellic acid. J Med Plant Res. 2010;4(25):2778-86.

37. Borrelli F, Capasso F, Capasso R, Ascione V, Aviello $\mathrm{G}$, Longo R, et al. Effect of Boswellia serrata on intestinal motility in rodents: inhibition of diarrhoea without constipation. $\mathrm{Br} \mathrm{J}$ Pharmacol. 2006;148(4):553-60.

38. Gupta I, Parihar A, Malhotra P, Gupta S, Lüdtke R, Safayhi H, et al. Effects of gum resin of Boswellia serrata in patients with chronic colitis. Planta Med. 2001;67(5):391-5.

39. Gerhardt H, Seifert F, Buvari P, Vogelsang H, Repges R. Therapy of active Crohn disease with Boswellia serrata extract H 15. Z Gastroenterol. 2001;39(1):117.

40. Gupta I, Parihar A, Malhotra P, Singh GB, Lüdtke R, Safayhi $\mathrm{H}$, et al. Effects of Boswellia serrata gum resin in patients with ulcerative colitis. Eur J Med Res. 1997;2(1):37-43.

Cite this article as: Thanawala S, Shah R, Katnapally $\mathrm{P}$, Bhatnagar U. Efficacy of standardized novel Boswellia serrata extract in the dextran sodium sulfate-induced colitis model - potential use in gut health management. Int J Basic Clin Pharmacol 2021;10:1352-9. 